\title{
TEM Study of High-Temperature Precipitation of Delta Phase in Inconel 718 Alloy
}

\author{
Moukrane Dehmas, ${ }^{1}$ Jacques Lacaze, ${ }^{2}$ Aliou Niang, ${ }^{2}$ and Bernard Viguier ${ }^{2}$ \\ ${ }^{1}$ IJL-SI2M UMR 7198 CNRS-Nancy Université-UPV Metz, École des Mines de Nancy, Parc de Saurupt, CS 14234, \\ 54042 Nancy Cedex, France \\ ${ }^{2}$ Institut Carnot CIRIMAT, Université de Toulouse, INP-ENSIACET, 4 allée Emile Monso, BP 44362, 31030 Toulouse Cedex 4, France
}

Correspondence should be addressed to Jacques Lacaze, jacques.lacaze@ensiacet.fr

Received 31 March 2011; Accepted 12 May 2011

Academic Editor: Joseph Lai

Copyright (C 2011 Moukrane Dehmas et al. This is an open access article distributed under the Creative Commons Attribution License, which permits unrestricted use, distribution, and reproduction in any medium, provided the original work is properly cited.

Inconel 718 is widely used because of its ability to retain strength at up to $650^{\circ} \mathrm{C}$ for long periods of time through coherent metastable $\gamma^{\prime \prime} \mathrm{Ni}_{3} \mathrm{Nb}$ precipitation associated with a smaller volume fraction of $\gamma^{\prime} \mathrm{Ni}_{3} \mathrm{Al}$ precipitates. At very long ageing times at service temperature, $\gamma^{\prime \prime}$ decomposes to the stable $\mathrm{Ni}_{3} \mathrm{Nb} \delta$ phase. This latter phase is also present above the $\gamma^{\prime \prime}$ solvus and is used for grain control during forging of alloy 718. While most works available on $\delta$ precipitation have been performed at temperatures below the $\gamma^{\prime \prime}$ solvus, it appeared of interest to also investigate the case where $\delta$ phase precipitates directly from the fcc matrix free of $\gamma^{\prime \prime}$ precipitates. This was studied by X-ray diffraction and transmission electron microscopy (TEM). TEM observations confirmed the presence of rotation-ordered domains in $\delta$ plates, and some unexpected contrast could be explained by double diffraction due to overlapping phases.

\section{Introduction}

Alloy 718 is the most widely used material for turbine disks and it is selected for many other applications as a high-strength material for temperatures up to $650^{\circ} \mathrm{C}$. This alloy was developed in the 60s when the former Fe-based superalloys evolved towards Ni-based superalloys. Alloy 718 contains both $\mathrm{Fe}$ and $\mathrm{Ni}$ alloyed with some $\mathrm{Al}$ and $\mathrm{Ti}$, though the most important addition is the refractory element $\mathrm{Nb}$. A typical composition of alloy 718 is reported in Table 1. It contains a small amount of carbon as well as very low levels of other species such as $\mathrm{Si}, \mathrm{Ta}, \mathrm{Mn}, \mathrm{Cu}, \mathrm{S}, \mathrm{B}, \mathrm{P}$, and $\mathrm{Mg}$, not listed in Table 1 but generally controlled.

The strength of alloy 718 comes from coherent solid-state precipitates, which are for a small part $\gamma^{\prime}-\mathrm{Ni}_{3} \mathrm{Al}$ but mostly $\gamma^{\prime \prime}-\mathrm{Ni}_{3} \mathrm{Nb}$ precipitates [1-6]. Both of these precipitates are ordered forms of the fcc-A1 Ni-rich matrix: $\mathrm{L}_{2}$ in the case of $\gamma^{\prime}$ and $\mathrm{DO}_{22}$ in the case of $\gamma^{\prime \prime}$. The solvus of these precipitates is at about $900-920^{\circ} \mathrm{C}$ as discussed previously [7]. Moreover, $\gamma^{\prime \prime}$ precipitates are metastable while the stable form of $\mathrm{Ni}_{3} \mathrm{Nb}$ is the so-called delta phase which is orthorhombic. Forging of 718 alloy is done at about $980^{\circ} \mathrm{C}$ slightly below the solvus of the delta phase, in such a way that this phase is sufficiently abundant to be effective in limiting grain growth but not too abundant to avoid significant $\mathrm{Nb}$ depletion in the matrix which would affect the subsequent strengthening by $\gamma^{\prime \prime}$ precipitation. This latter precipitation is generally obtained after two successive periods of isothermal ageing at $750^{\circ} \mathrm{C}$ and $650^{\circ} \mathrm{C}$, respectively.

Precipitation of delta phase proceeds through a discontinuous reaction starting at grain boundaries and an intragranular precipitation of thin plates. It has been reported that the former reaction predominates at low temperatures whilst the latter is more characteristic of intermediate temperatures [2], but no systematic and quantitative study has been performed on that aspect. At high temperatures, both types of precipitates may be observed as illustrated in Figure 1.

In fully strengthened material, precipitation of delta has been studied for many years at both low and intermediate temperatures as it corresponds to a dramatic decrease of the mechanical properties of alloy 718. Kirman and Warrington [2] showed that the growth of $\delta$ at the expense of $\gamma^{\prime \prime}$ 
TABLE 1: Specification (wt.\%) of alloy 718 [8] and composition of the alloys used in the present study $[7,9]$.

\begin{tabular}{lccccccccc}
\hline & $\mathrm{Ni}$ & $\mathrm{Fe}$ & $\mathrm{Cr}$ & $\mathrm{Nb}$ & $\mathrm{Ti}$ & $\mathrm{Al}$ & $\mathrm{Mo}$ & $\mathrm{C}$ & $\mathrm{Co}$ \\
\hline Specification & $50.0-55.0$ & Balance & $17.0-21.0$ & $4.75-5.50$ & $0.75-1.15$ & $0.20-0.80$ & $2.80-3.30$ & $<0.08$ & - \\
Alloy 1 [9] & 54.4 & 17.4 & 17.9 & 5.4 & 1.1 & 0.5 & 3.0 & 0.02 & 0.2 \\
Alloy 2 [7] & 53.0 & 17.1 & 17.5 & 5.3 & 1.1 & 0.5 & 3.1 & 0.12 & 0.2 \\
\hline
\end{tabular}

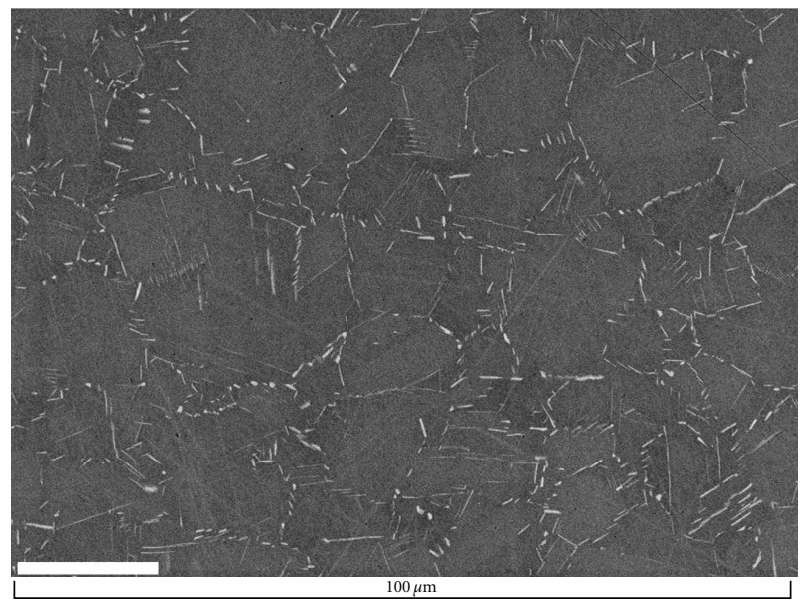

FIGURE 1: SEM micrograph showing mainly cellular (grain boundary) and some intragranular precipitation of delta phase in a sample held for $1 \mathrm{~h}$ at $960^{\circ} \mathrm{C}$.

precipitates is often associated with the formation of faults within the $\gamma^{\prime \prime}$. By means of dark field imaging, these authors observed that the faults are illuminated together with the related delta plate, and they concluded that the formation of these faults is the first step in the transformation of metastable to stable $\mathrm{Ni}_{3} \mathrm{Nb}$ precipitates. These observations have been repeated more recently by Sundararaman et al. [10]. Further details on the faults appearing in $\gamma^{\prime \prime}$ precipitates have been previously presented by our group [11].

The only report of TEM examination of a material aged at a temperature above the $\gamma^{\prime \prime}$ solvus is due to Sundararaman et al. [10]. In a sample held at $950^{\circ} \mathrm{C}$, these authors observed only the presence of delta phase as expected but did not give any details and in particular no diffraction diagram was recorded. The present work was intended to pursue the investigation of the growth conditions of delta phase at high temperature. X-ray diffraction results and TEM observations are reported.

\section{Material and Methods}

Two Inconel 718 alloys were used in this investigation, supplied, respectively, by Special Metals Corporation (denoted alloy 1 in the following) and by Aubert and Duval (denoted alloy 2). The amounts of the main elements in their composition are listed in Table 1, further details having been given previously $[7,9]$.

As described previously [9], alloy 1 in the as-received state showed a microstructure very similar to that of a fully strengthened material, that is, some residual delta phase
TABle 2: Structural parameters for $\delta$ phase at $25^{\circ} \mathrm{C}$ : Pmmn (no. 59) with $a=5.114 \AA, b=4.244 \AA$, and $c=4.538 \AA$ [13].

\begin{tabular}{lccccc}
\hline & Wyckoff & $x$ & $Y$ & $z$ & Occupancy \\
\hline $\mathrm{Ni}(1)$ & $2 \mathrm{a}$ & 0 & 0 & 0.3182 & 1 \\
$\mathrm{Ni}(2)$ & $4 \mathrm{f}$ & 0.7494 & 0 & 0.8414 & 1 \\
$\mathrm{Nb}(1)$ & $2 \mathrm{~b}$ & 0 & $1 / 2$ & 0.6513 & 1 \\
\hline
\end{tabular}

precipitates mainly at grain boundaries and a high volume fraction of small $\gamma^{\prime \prime}$ precipitates within the grains. Samples of this material were aged for various times at $960^{\circ} \mathrm{C}$ or $920^{\circ} \mathrm{C}$ and then air cooled. Alloy 2 was received in the fully strengthened state and the specimens studied here were aged for $3 \mathrm{~h}$ at $960^{\circ} \mathrm{C}$.

XRD profiles were all recorded on samples from alloy 1 using a diffractometer with $\mathrm{Cu}-\mathrm{K}_{\alpha}$ radiation $\left(\lambda_{\mathrm{cu}}=\right.$ $1.54184 \AA)$, with the power fixed at $4 \mathrm{~kW}(40 \mathrm{kV}$ and $100 \mathrm{~mA}$ ). The instrument was set up for Bragg-Brentano geometry with a line focus and a graphite monochromator in diffracted beam arm. During the scans $2 \theta$ ranged between 10 and $100^{\circ}$ with an angular step of $0.025^{\circ}$ and 30 s counting time at each step. As the volume fraction of the delta phase is low even after heat-treatment, the precipitates were also electrolytically extracted from the heat-treated specimens for $\mathrm{X}$-ray characterization. The solution used to dissolve the matrix consisted of $1 \mathrm{~mL}$ ammonium sulfate, $2 \mathrm{~mL}$ tartaric acid, and $97 \mathrm{~mL}$ water. The current was set at $100 \mathrm{~mA} / \mathrm{cm}^{2}$ and the time for extraction was 5 to $6 \mathrm{~h}$ [12]. From the structural data reported in the literature for the $\delta$ phase [13], and listed in Table 2, an initial set of lattice parameters was obtained by least-square refinement using DICVOL software [14]. Then, structure refinement was carried out by Rietveld analysis of the X-ray powder diffraction data with FullProf software [15]. An account of the mathematical procedures implemented in the Rietveld analysis [16] is summarized in the appendix.

For microstructural investigation by TEM, thin foils were prepared by cutting, mechanical thinning down to a thickness of about $50 \mu \mathrm{m}$, and jet polishing in a TenuPol5 at $-10^{\circ} \mathrm{C}$ and a voltage of $22 \mathrm{~V}$. The electrolyte was one part perchloric acid, two parts butylcellosolve, and nine parts methanol. The samples were investigated using either a Philips CM20 or a JEOL 2100F, both operating at an acceleration voltage of $200 \mathrm{kV}$.

\section{Results}

3.1. X-Ray Diffraction. Figure 2 shows the whole X-ray diagram recorded on a sample of alloy 1 aged for $1 \mathrm{~h}$ at $960^{\circ} \mathrm{C}$. 


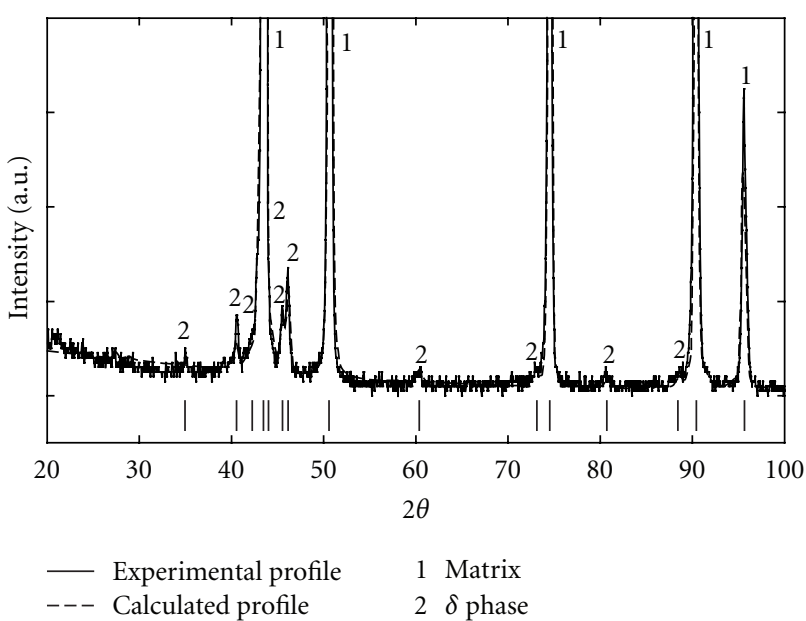

Figure 2: Whole experimental X-ray diagram with first indexation of the lines, showing that all the peaks may be attributed to either the fcc matrix or the delta phase.

Through least-squares refinement, the XRD pattern is fully indexed on a cubic lattice (fcc matrix) with unit cell parameter of $3.604 \AA$ and a orthorhombic lattice ( $\delta$ phase) with unit cell parameters $a=5.108 \AA, b=4.214 \AA$, and $c=4.521 \AA$ (volume $V=97.315 \AA^{3}$ ). All peaks in Figure 2 are indexed and there is no evidence of any other phase present, such as $\gamma^{\prime}$ or $\gamma^{\prime \prime}$.

For further exploitation of the X-ray diagrams on bulk samples, the parameters of the delta phase were then evaluated from the X-ray pattern acquired on the extracted precipitates. Figure 3 shows the experimental diagram for $2 \theta$ between $39^{\circ}$ and $49^{\circ}$, in which the peak at $43.51^{\circ}$ is associated to some remains of the matrix and/or the $\gamma^{\prime \prime}$ phase while all other peaks come from the delta phase. To optimally adjust all the delta phase intensities from the initial structural model [13], the atomic positions were refined by Rietveld's method. The refinement was constrained by the space group with its respective Wyckoff's positions as given in Table 2. Then these atom positions were fixed to allow for the refinement of the site occupancies as a function of one of the following conditions:

(A) $\mathrm{Nb}$ site occupancy fixed, the sum of the Ni site occupancies is equal to 1 ;

(B) $\mathrm{Nb}$ site occupancy fixed, $\mathrm{Ni}$ site occupancies are independent;

(C) the three site occupancies are independent.

Rietweld refinement gave similar results for all three conditions. The X-ray diagram calculated for condition (A) was superimposed on the experimental diagram in Figure 3. The amount of remaining matrix was adjusted so that the height of the calculated peak at $43.51^{\circ}$ corresponds to the experimental value. Similarly, the amount of delta phase was fixed so that the height of its most intense peak at $46.11^{\circ}$ agrees with the experimental value. It is seen that most of the other peaks of the delta phase are well reproduced by calculation apart from the one at $42.99^{\circ}$ which corresponds

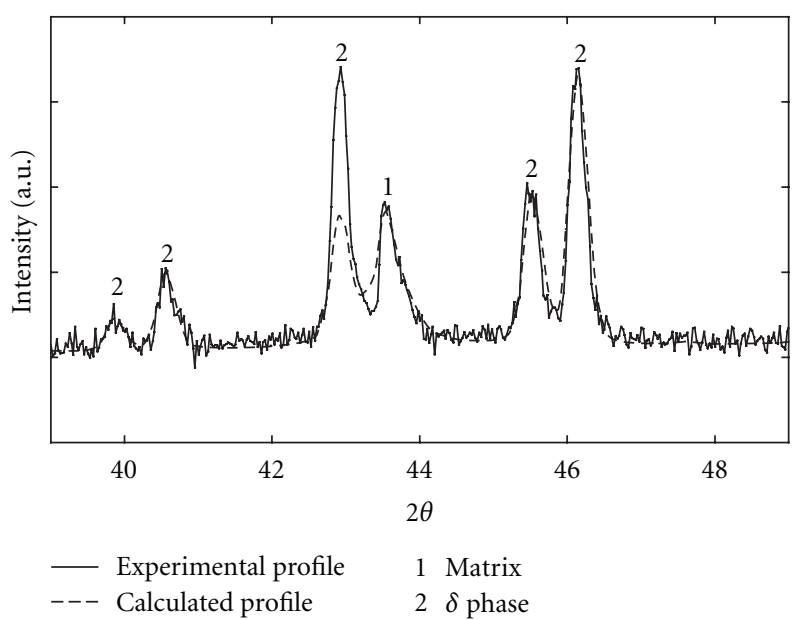

Figure 3: Experimental and calculated X-ray diagram corresponding to precipitates extracted from the material. The diagram was calculated after Rietveld refinement according to condition (A).

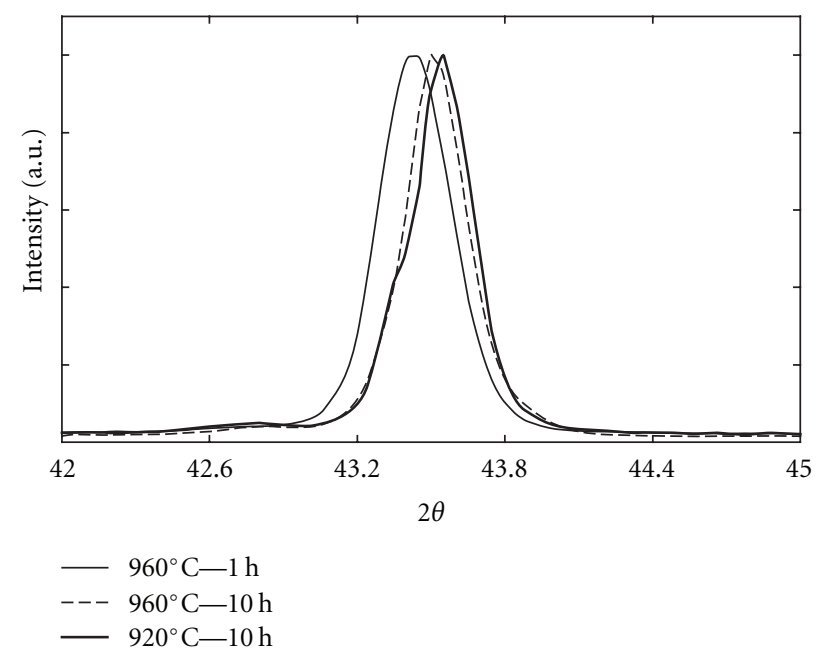

FIGURE 4: XRD pattern showing angular displacement of the (111) matrix peak as function of ageing treatment.

to the close packed (020) plane of delta phase. This is certainly related to the shape of the delta precipitates that are mainly thin discs grown in the (020) plane after heat treating for $1 \mathrm{~h}$ at $960^{\circ} \mathrm{C}$ [9].

XRD profiles were then recorded on samples aged for various times and temperatures, thus showing various amounts of delta phase. It was found that the change of the parameters of the delta phase was not significant while the matrix parameter clearly proved to be affected. This is illustrated in Figure 4 which presents the (111) peak of the matrix for the three samples investigated. A significant shift is seen in the peak position from one sample to another which could certainly be related to alterations of the volume fraction of delta phase as evaluated by image analysis [9]. Rietveld refinement of the X-ray diagrams was also performed to evaluate the volume fraction of delta precipitates in these samples. The structural model for condition (A) obtained 
TABLE 3: Volume fraction (\%) of delta phase after different ageing treatments obtained by image analysis [9] and by Rietveld refinement.

\begin{tabular}{lcc}
\hline Ageing conditions & $\begin{array}{c}\text { Image analysis } \\
{[9]}\end{array}$ & $\begin{array}{c}\text { Rietveld } \\
\text { Refinement }\end{array}$ \\
\hline $960^{\circ} \mathrm{C}-1 \mathrm{~h}$ & 2.3 & 2.5 \\
$960^{\circ} \mathrm{C}-10 \mathrm{~h}$ & 5.6 & 6.2 \\
$920^{\circ} \mathrm{C}-10 \mathrm{~h}$ & 7.3 & 7.8 \\
\hline
\end{tabular}

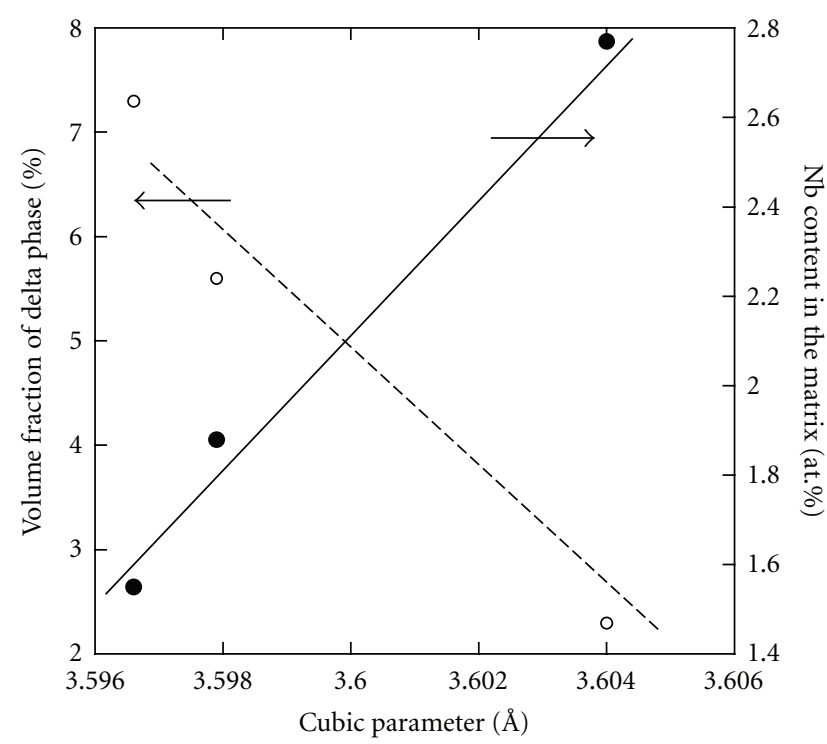

FIGURE 5: Variation of lattice parameter of the matrix versus volume fraction of delta phase and niobium content in the matrix.

from the precipitate extracted from the bulk specimen was used for this purpose. The data obtained are compared in Table 3 to image analysis results and both techniques give values in quite good agreement.

Finally, Figure 5 shows the lattice parameter of the matrix as a function of the volume fraction of delta phase and of the niobium content of the matrix, $x_{\mathrm{Nb}}^{\gamma}$ (at.\%), that was evaluated considering that the delta phase is the binary stoichiometric $\mathrm{Ni}_{3} \mathrm{Nb}$ phase. It is seen that the lattice parameter of the matrix decreases more or less linearly with increasing volume fraction of delta phase, that is, obeying a Vegard law such as: $a^{\gamma}=3.587+0.0062 \cdot x_{\mathrm{Nb}}^{\gamma}(\AA)$. The effect of $\mathrm{Nb}$ substitution on the fcc matrix agrees well with the value of $0.007 \AA(\text { at. } \%)^{-1}$ estimated from the data assessed by P. Nash and A. Nash for the binary Ni-Nb system [17].

3.2. TEM Observation. It has been shown previously that nucleation of delta phase is difficult in a material free of $\gamma^{\prime \prime}$ precipitates [7]. We therefore investigated the first stage of delta phase growth by TEM. The first TEM observations were performed on a sample of alloy 1 aged for $1 \mathrm{~h}$ at $960^{\circ} \mathrm{C}$. A typical bright field micrograph showing a platelike precipitate is shown in Figure 6. Two areas labeled as 1

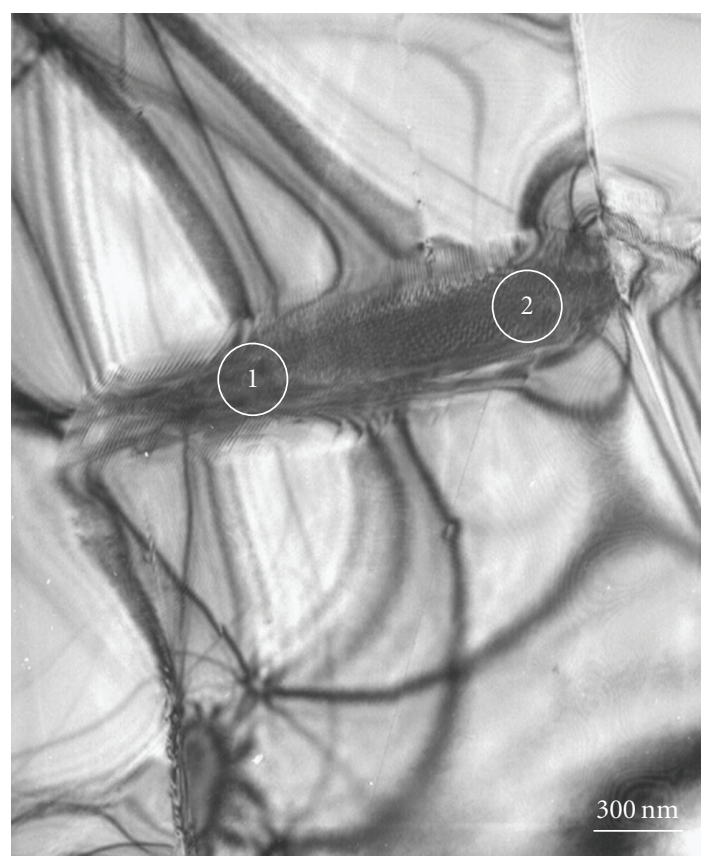

FIGURE 6: Bright field image of a plate-like precipitate with locations 1 and 2 used for recording SAD pattern.

and 2 were selected for electron diffraction and the selected area diffraction $(\mathrm{SAD})$ patterns corresponding to the $[111]_{\gamma}$, $[001]_{\gamma}$ zone axis of the matrix were recorded.

The SAD patterns along the $[111]_{y}$ zone axis obtained on the matrix and on the precipitate in location 1 are shown in Figures 7(a) and 7(b). The pattern in Figure 7(b) was easily indexed as the one corresponding with the $[010]_{\delta}$ zone axis. The orientation relationship between the $\gamma$ matrix and the $\delta$ phase is thus $(111)_{\gamma} / /(010)_{\delta}$ and $[\overline{1} 01]_{\gamma} / /[100]_{\delta}$. This relationship is the same as the one that has been reported after ageing at lower temperatures [18], and simply corresponds to the alignment of compact planes and dense directions in both structures. The SAD pattern obtained with the same conditions in location 2 is presented in Figure $7(\mathrm{c})$. The additional spots observed in this latter SAD pattern, arise from a mirror image of the pattern in Figure $7(\mathrm{~b})$ with respect to the $(2 \overline{2} 0)_{\gamma}$ plane. These spots can also be indexed as belonging to a second variant of the $\delta$ phase with an orientation relationship to the matrix $\gamma$ given by $(111)_{\gamma} / /(010)_{\delta 2}$ and $[0 \overline{1} 1]_{\gamma} / /[100]_{\delta 2}$. In fact, close observation of the pattern in Figure 7(b) also shows faint dots from this second variant.

A striking figure was obtained when looking at the SAD of the plate along the $[001]_{y}$ zone axis of the matrix. Figure 8(a) shows the pattern recorded on the matrix, Figures $8(\mathrm{~b})$ and $8(\mathrm{c})$ show those obtained on the plate in locations 1 and 2, respectively. The presence of two variants is again observed in location 2, with one of them being as before the variant showing up in location 1. Astonishingly enough, the pattern in Figure 8(b) is indexed according to the metastable $\gamma^{\prime \prime}$ phase with the usual orientation relationship to the matrix: $(001)_{\gamma} / /(100)_{\gamma^{\prime \prime}}$ and $[010]_{\gamma} / /[001]_{\gamma^{\prime \prime}}$. 


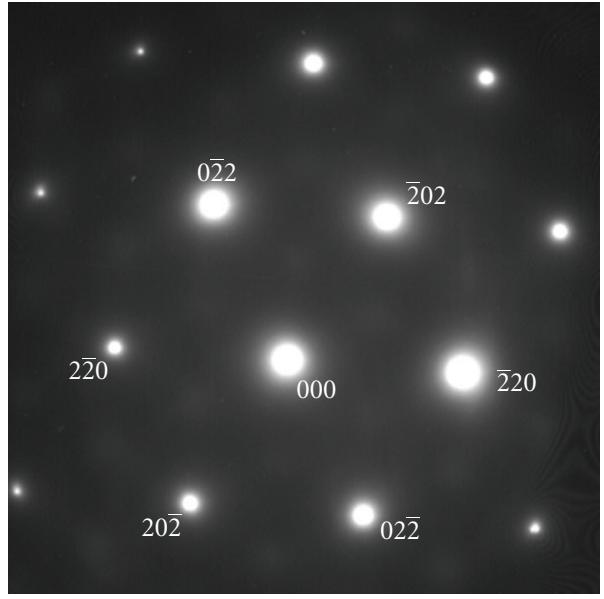

(a)

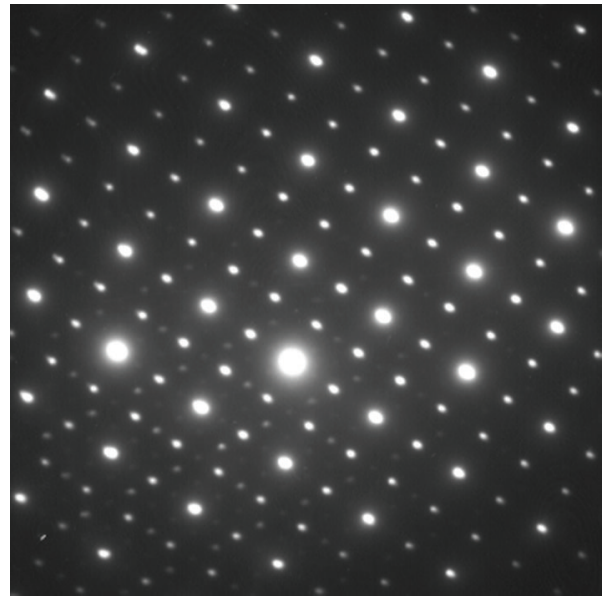

(b)

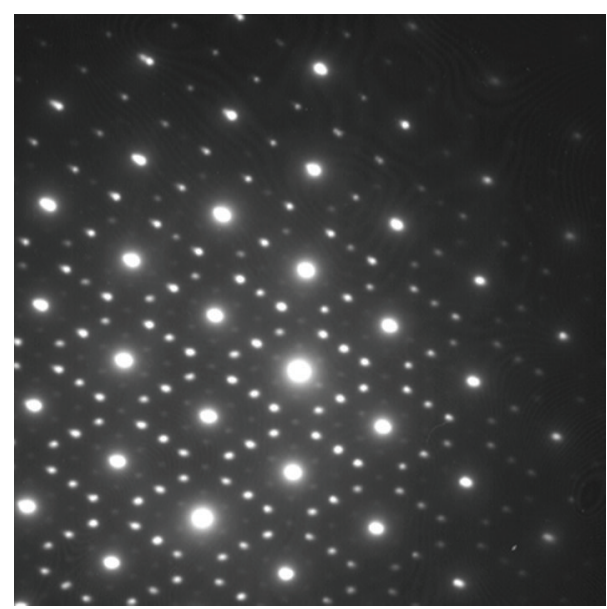

(c)

Figure 7: Experimental SAD patterns of the matrix (a) and in locations 1 (b) and 2 (c) of the precipitate shown in Figure 6. The patterns were identified as the $[111]_{\gamma}$ zone axis for the matrix (a) and the $[010]_{\delta}$ for the delta plate (b). In location 2, a second variant of the delta phase appears together with that in location 1 (c).

Apparently, this pattern cannot be directly related to the delta phase. In location 2, the pattern is thus apparently the superposition of two variants of the $\gamma^{\prime \prime}$ phase along the $[100]_{\gamma^{\prime \prime}}$ and $[010]_{\gamma^{\prime \prime}}$ zone axes, respectively.

Using the CaRIne Crystallography software [19] to simulate the SAD patterns, it was noticed that the reflections of $\gamma^{\prime \prime}$ are superimposed on the $\delta$ phase for $[111]_{\gamma}$ and those of $\delta$ are superimposed on the $\gamma^{\prime \prime}$ phase for $[010]_{\gamma}$ for both variants. These results suggest that the plate-like precipitate may contain both phases, namely, $\gamma^{\prime \prime}$ and $\delta$. Dark field images with $\gamma^{\prime \prime}$ spots seemed to indicate that this phase surrounds the $\delta$ plate. However, these images were not clear and it appeared necessary to resort to high-resolution TEM (HRTEM) to decide whether that precipitation of delta from the gamma matrix involves an intermediate $\gamma^{\prime \prime}$ precipitate even at temperatures where it is not expected to appear.

This second part of the TEM investigation was carried out on a sample of alloy 2 aged for $3 \mathrm{~h}$ at $960^{\circ} \mathrm{C}$ and then quenched. This sample thus contained $\delta$ phase that precipitated at the grain boundaries and in the grains, both in the form of plates. By selecting appropriate areas in the thin foil we successively studied the two phenomena illustrated in the $\delta$ plate observed in Figure 6: the existence of different variants of the ordered phases and the concomitant presence of $\delta$ and $\gamma^{\prime \prime}$ within the same precipitate.

Figure 9 shows TEM images of a $\delta$ platelet lying parallel to the $(111)_{\gamma}$ plane and observed along the $[\overline{1} 01]_{\gamma}$ direction. In the low-magnification image, Figure 9(a), different areas can be seen in the platelet, for example, those labeled $\delta_{1}$ and $\delta_{2}$. The borders between these areas are shown with solid lines in Figure 9(a). A closer observation of this boundary is reported in Figure 9(b) showing lattice imaging of the different phases. Examination of these images and the corresponding Fourier transforms (obtained with ImageJ software [20]) indicated that the $\delta$ platelet is a coherent precipitate in the $\gamma$ matrix, with the habit plane $(111)_{\gamma} / /(010)_{\delta}$. The Fourier transform patterns showed that the areas labeled $\delta_{1}$ and $\delta_{2}$ correspond to different orientations of the orthorhombic phase along $[\overline{101}]_{\gamma} / /[100]_{\delta 1}$ and $[\overline{101}]_{\gamma} / /[102]_{\delta 2}$, respectively. In the $\delta$ structure, the $[102]_{\delta}$ axis is rotated $2 \pi / 3$ 


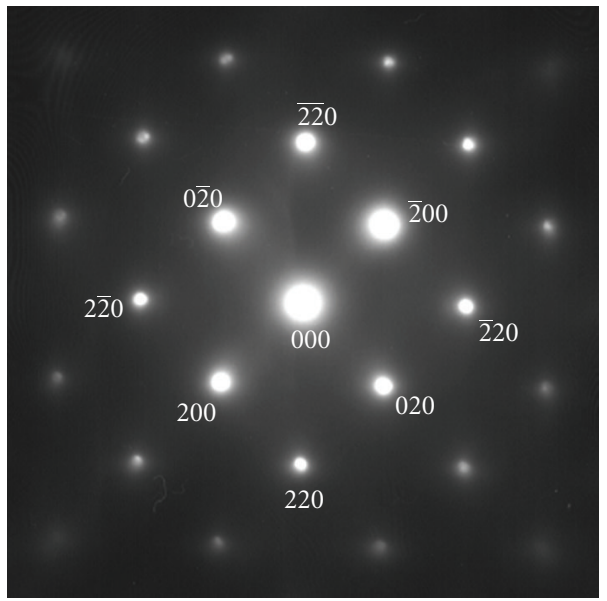

(a)

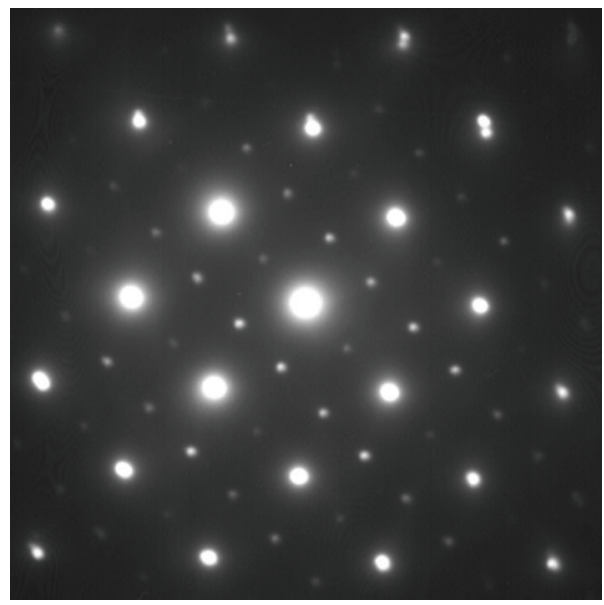

(b)

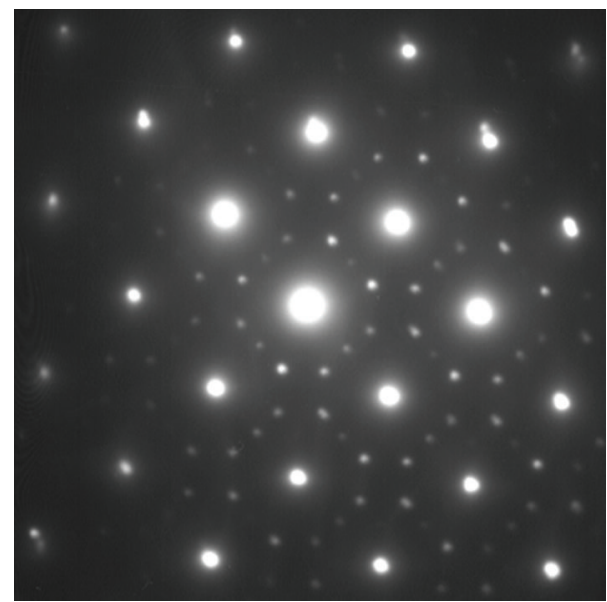

(c)

FIGURE 8: Experimental SAD patterns of the matrix (a) and of the precipitate seen Figure 6 in locations 1 (b) and 2 (c). The patterns were identified as the $[001]_{\gamma}$ zone axis for the matrix (a), the $[100]_{\gamma^{\prime \prime}}$ for location 1 , and the $[100]_{\gamma^{\prime \prime}}$ and $[010]_{\gamma^{\prime \prime}}$ for location 2.

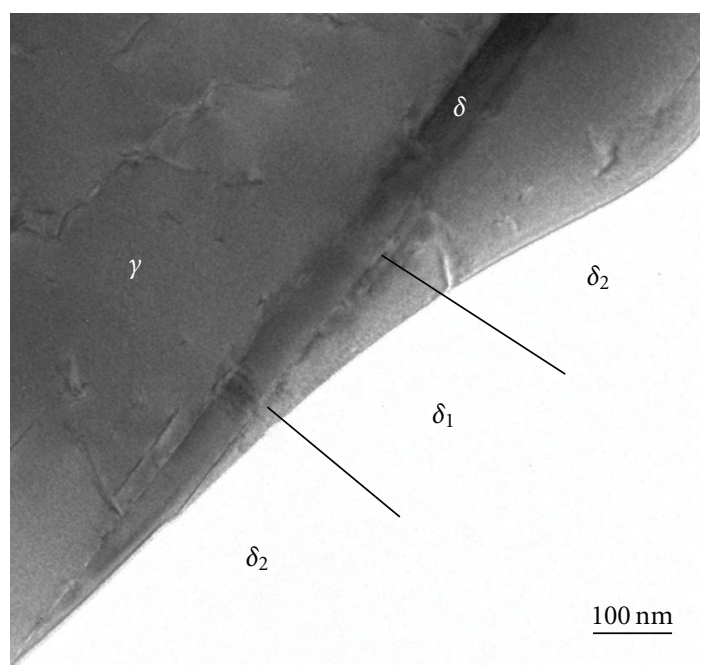

(a)

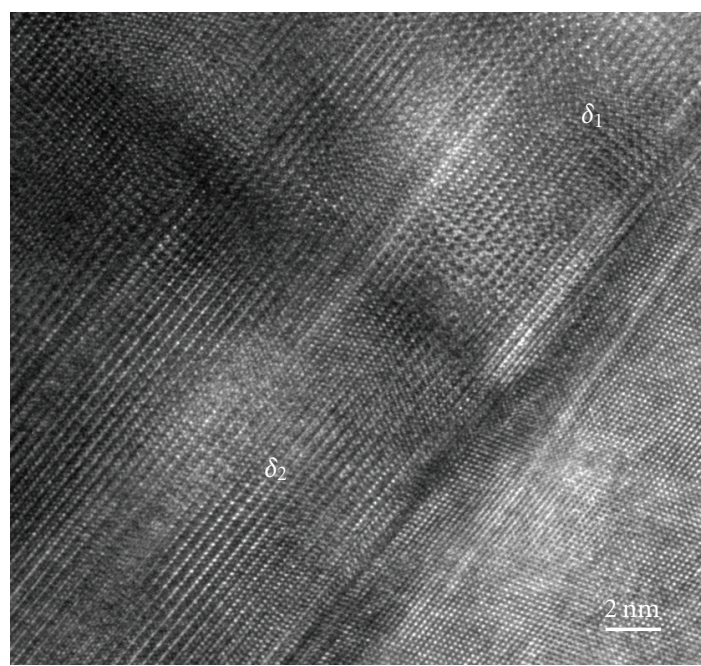

(b)

FIGURE 9: TEM observation of a $\delta$ platelet in a 718 alloy sample aged $3 \mathrm{~h}$ at $960^{\circ} \mathrm{C}$. The low-magnification bright field image in (a) shows the extent of different variants of the $\delta$ phase, detailed in the HRTEM image of the same sample in (b). 
away from $[100]_{\delta}$, so that the latter orientation relationship corresponds to $(111)_{\gamma} / /(010)_{\delta 2}$ and $[0 \overline{1} 1]_{\gamma} / /[100]_{\delta 2}$. The two areas observed in Figure 9 thus confirmed the existence of two variants of the $\delta$ phase in a given precipitate. Such variants have been previously reported by Zhang et al. [21] and described in terms of orientation twins or antiphase domain structures. Indeed the variants only differ by the orientation of the $[100]_{\delta}$ direction in the $(010)_{\delta}$ plane with respect to different $\langle 110\rangle_{\gamma}$ directions of the $(111)_{\gamma}$ plane.

Further HRTEM investigation of the same sample showed that the boundary between delta precipitates and the matrix could present unexpected contrast. This is illustrated in Figure 10 that was obtained along the $[\overline{1} 01]_{\gamma}$ zone axis of the matrix and shows the extremity of a $\delta$ precipitate. The interfaces between precipitate and matrix parallel to $(111)_{\gamma}$ and $(010)_{\delta}$ planes are sharply defined and show ledges. The third interface shows a very different contrast with the occurrence of fringes parallel to the $(111)_{\gamma}$ plane. These fringes repeat every six $(111)_{\gamma}$ planes which recalls the stacking sequence of six compact planes in the $\gamma^{\prime \prime}$ phase $\left(A_{1} B_{1} C_{1} A_{2} B_{2} C_{2} \ldots\right.$ as described by Paulonis et al. [1]). Fourier transforms of the image in the different areas labeled a, b, and c in Figure 10 are shown in Figure 11. The first two correspond, respectively, to the SAD pattern of the matrix along $[\overline{101}]_{\gamma}$ zone axis and delta phase along $[100]_{\delta}$ zone axis, as shown by the schematic illustration of the indexation in Figure 11.

The third pattern, obtained by the Fourier transformation of the interfacial area $c$ in Figure 10, cannot be indexed as a diffraction pattern of $\gamma^{\prime \prime}$ phase along the various possible directions (either $[110]_{\gamma^{\prime \prime}}$ or $[201]_{\gamma^{\prime \prime}}$ type) that would have been compatible with the orientation relation between $\gamma$ and $\gamma^{\prime \prime}$. In the corresponding schematic indexation, it is seen that the pattern consists of the superimposition of the two first patterns plus additional points. These points could in fact all be deduced by translations of $\delta$ or $\gamma$ spots by a vector $\pm 1 / 3(010)_{\delta}=1 / 6(111)_{\gamma}$. Such a vector is given for instance by connecting $(\overline{1} 1 \overline{1})_{\gamma}$ and $(0 \overline{1} 2)_{\delta}$ as illustrated in Figure 11(c). This corresponds to double diffraction phenomena and leads to the conclusion that the fringes observed are due to the superimposition of $\gamma$ and $\delta$ phases. Such a superimposition and the associated fringes have been reported by Chen et al. [22] in TiAl alloys where the phases involved were the $\mathrm{L}_{0}$-gamma and $\mathrm{DO}_{19}$-alpha phases.

This analysis allowed us to reconsider the interpretation of the SAD patterns presented in Figure 8. Indeed the orientation relationship between the matrix $\gamma$ and the $\delta_{1}$ phase indicates that the $[001]_{\gamma}$ direction is parallel to the $[\overline{3} 32]_{\delta 1}$ direction. The corresponding diffraction patterns are shown in Figures 12(a) and 12(b), respectively. The superimposition of these two patterns which is given in Figure 12(c) shows that, when considering double diffraction (e.g., the arrows in Figure 12(c)), all the spots observed in Figure 8(b) could be explained solely by the presence of $\gamma$ and $\delta$ phases. For completeness, we may remark that the diffraction pattern in Figure 8(c) is simply explained in the same way by the mirror symmetry about the $(2 \overline{2} 0)_{\gamma}$ plane, already noted in Figure 7.

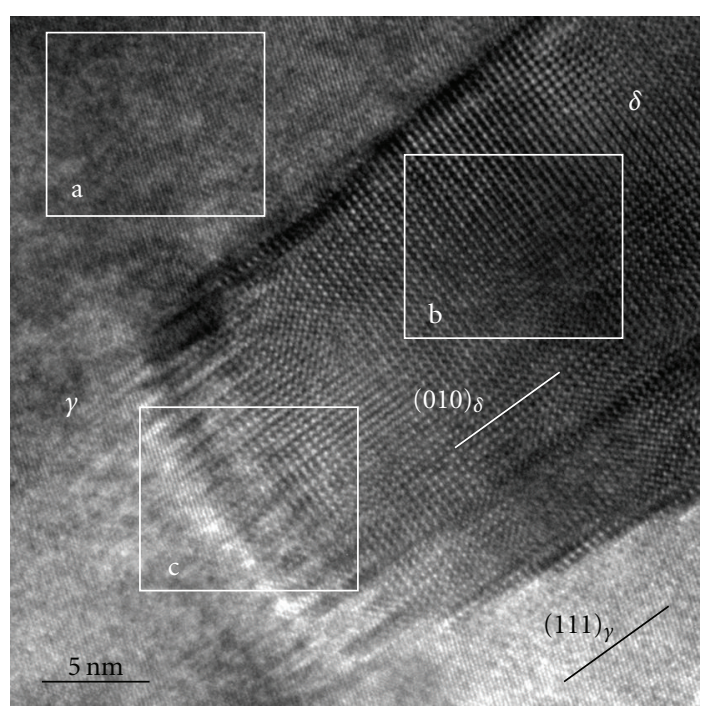

FIgURE 10: HRTEM image taken on a sample held for $3 \mathrm{~h}$ at $960^{\circ} \mathrm{C}$.

Similar observations were conducted on specimens of the 718 alloy after different heat treatments. When extra spots were observed on SAD patterns they could always be explained by such double diffraction. Accordingly, it may be stated that $\gamma^{\prime \prime}$ was not present on the edges of the delta precipitates as could have been erroneously guessed from the SAD patterns in Figure 8.

\section{Conclusion}

The precipitation of $\delta$ phase at high temperature from a supersaturated matrix (i.e., without $\gamma^{\prime \prime}$ phase) was studied by XRD and TEM. Rietveld refinement proved to be very efficient to study $\delta$ precipitation. The volume fraction of $\delta$ precipitates was determined and allowed us to calculate the alterations occurring in the $\gamma$ cell parameter with the amount of dissolved $\mathrm{Nb}$. The results confirm the close correlation between $\delta$ precipitate growth kinetics and the evolution of the niobium content in the matrix. Detailed TEM studies of the $\delta$ platelets confirmed the existence of antiphase domains related by a $2 \pi / 3$ rotation around the $[010]_{\delta}$ axis. Some diffraction contrast observed at the edges of delta precipitates could lead to the erroneous conclusion that delta phase grows through the formation of an intermediate $\gamma^{\prime \prime}$ phase. Examination of the Fourier transforms from the images showed that the contrast observed is due to a double diffraction phenomenon occurring when $\gamma$ and $\delta$ phases overlap. The present investigations thus indicate that $\delta$ phase may grow directly from the supersaturated $\gamma$ matrix.

\section{Appendix}

Considering the integrated intensity of the peaks to be a function of the refined structural parameters, a least-squares procedure was used to minimize the difference between the observed and simulated powder diffraction patterns. The progress of the minimization was monitored through 

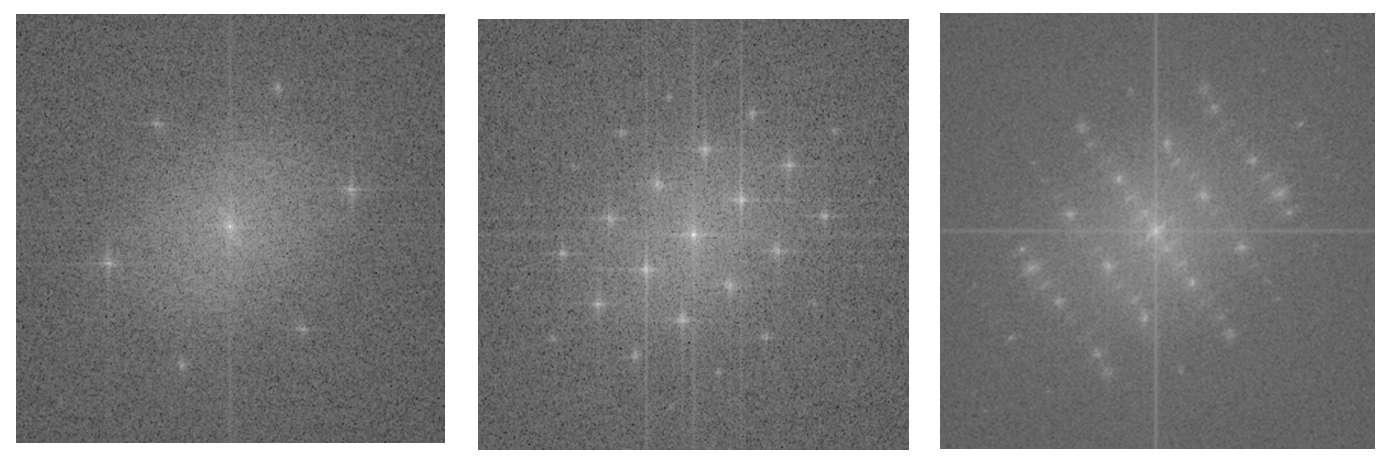

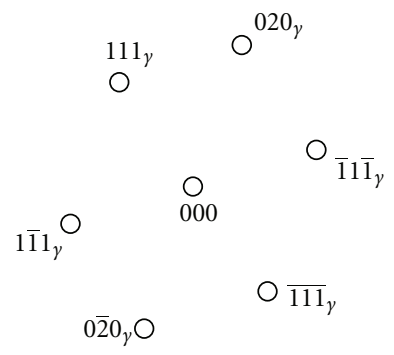

(a)

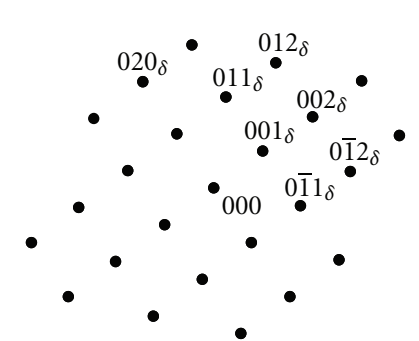

(b)

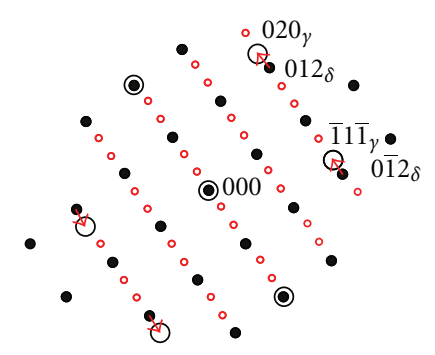

(c)

FIgURE 11: Fourier transform of zones a, b, and c in Figure 10 (first row) and their indexing (second row).

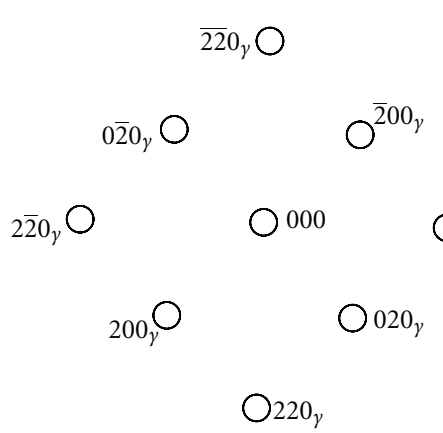

(a) $\overline{22} 0_{\delta}$

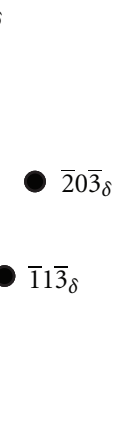

(b)

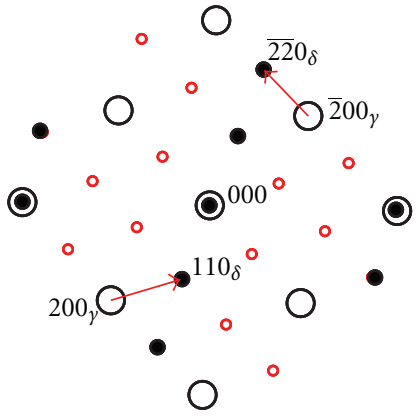

(c)

FIGURE 12: Indexing of the SAD pattern shown in Figure 8(b), indicating that the pattern can be obtained by the superimposition of diffraction along $[001]_{\gamma}$ (a) and $[\overline{3} 32]_{\delta 1}$ (b) plus some additional spots arising from double diffraction as shown by the arrows in (c).

the usual reliability parameters, $R_{\mathrm{wp}}$ (weighted residual factor) and $R_{\exp }$ (expected residual factor) defined as:

$$
\begin{gathered}
R_{\mathrm{wp}}=\left[\frac{\sum_{2 \theta} w_{2 \theta}\left(I_{\exp }(2 \theta)-I_{\mathrm{calc}}(2 \theta)\right)^{2}}{\sum_{2 \theta} w_{2 \theta}\left(I_{\exp }(2 \theta)\right)^{2}}\right]^{1 / 2}, \\
R_{\exp }=\left[\frac{N-P}{\sum w_{2 \theta}\left(I_{\exp }(2 \theta)\right)^{2}}\right]^{1 / 2},
\end{gathered}
$$

where $I_{\exp }(2 \theta)$ and $I_{\text {calc }}(2 \theta)$ are the experimental and calculated intensities at $2 \theta$ angles, $w_{2 \theta}=1 / I_{\exp }(2 \theta)$ are weight factors, $N$ is the number of experimental observations, and
$P$ is the number of refined parameters. Also, we used the socalled goodness of fit ( GoF) factor given as

$$
\mathrm{GoF}=\frac{R_{\mathrm{wp}}}{R_{\exp }}
$$

Refinements were carried out until convergence was reached and the value of the GoF factor became close to 1 (usually, the final GoF varies from 1.1 to 1.3 ). The parameters that were refined using FullProf are the following:

(i) background;

(ii) unit cell parameters;

(iii) breadth of peaks (a Pearson VII profile function was found to be best suited to fit the experimental peaks); 
(iv) scale factors $\left(S_{i}\right)$, which are related to the mass fraction $\left(x_{i}\right)$ of the phase $i$ in the mixture by

$$
x_{i}=\frac{\left(S_{i} Z M_{i} V_{i}\right) / t_{i}}{\sum_{i}\left(S_{i} Z M_{i} V_{i}\right) / t_{i}},
$$

where $Z$ is the number of formula units per unit cell for phase $i, M$ is the mass of the formula unit, $V$ is the unit cell volume, and $t$ is the Brindley coefficient that accounts for microabsorption effects.

Then, the volume fraction $\left(f_{i}\right)$ of phase $i$ can be calculated from the mass fraction as:

$$
f_{i}=\frac{x_{i} / \rho_{i}}{\sum_{i} x_{i} / \rho_{i}},
$$

where $\rho_{i}$ is the density of phase $i$.

\section{Acknowledgment}

The authors very much appreciated the possibility of using transmission electron microscopes at CEMES and TEMSCAN in Toulouse.

\section{References}

[1] D. F. Paulonis, J. M. Oblak, and D. S. Duvall, "Precipitation in nickel-base alloy 718," Trans. ASM, vol. 62, no. 3, pp. 611-622, 1969.

[2] I. Kirman and D. H. Warrington, "The precipitation of $\mathrm{Ni3Nb}$ phases in a Ni-Fe-Cr-Nb alloy," Metallurgical Transactions, vol. 1, no. 10, pp. 2667-2675, 1970.

[3] R. Cozar and A. Pineau, "Morphology of y' and y" precipitates and thermal stability of inconel 718 type alloys," Metallurgical Transactions, vol. 4, no. 1, pp. 47-59, 1973.

[4] J. M. Oblak, D. F. Paulonis, and D. S. Duvall, "Coherency strengthening in Ni base alloys hardened by DO22 $\gamma^{\prime}$ precipitates," Metallurgical Transactions, vol. 5, no. 1, pp. 143-153, 1974.

[5] M. Sundararaman, P. Mukhopadhyay, and S. Banerjee, "Some aspects of the precipitation of metastable intermetallic phases in INCONEL 718," Metallurgical transactions. A, vol. 23, no. 7, pp. 2015-2028, 1992.

[6] C. Slama, C. Servant, and G. Cizeron, "Aging of the Inconel 718 alloy between 500 and $750 \circ$ C," Journal of Materials Research, vol. 12, no. 9, pp. 2298-2316, 1997.

[7] A. Niang, B. Viguier, and J. Lacaze, "Some features of anisothermal solid-state transformations in alloy 718," Materials Characterization, vol. 61, no. 5, pp. 525-534, 2010.

[8] L. Yang, K. M. Chang, S. Mannan, and J. D. Barbadillo, "Superalloys 718, 625, 706 and various derivatives," in Proceedings of the 6th International Symposium on Superalloys 718, 625, 706 and Derivatives, E. A. Loria, Ed., pp. 353-365, TMS, 1997.

[9] V. Beaubois, J. Huez, S. Coste, O. Brucelle, and J. Lacaze, "Short term precipitation kinetics of delta phase in strain free Inconel* 718 alloy," Materials Science and Engineering, vol. 20, no. 8, pp. 1019-1026, 2004.

[10] M. Sundararaman, P. Mukhopadhyay, and S. Banerjee, "Precipitation of the $\delta$-Ni3 $\mathrm{Nb}$ phase in two nickel base superalloys," Metallurgical Transactions A, vol. 19, no. 3, pp. 453-465, 1988.
[11] A. Niang, J. Huez, J. Lacaze, and B. Viguier, "Characterizing precipitation defects in nickel based 718 alloy," Materials Science Forum, vol. 636-637, pp. 517-522, 2010.

[12] R. B. Li, M. Yao, W. C. Liu, and X. C. He, "Isolation and determination for $\delta, \gamma^{\prime}$ and $\gamma^{\prime \prime}$ phases in Inconel 718 alloy," Scripta Materialia, vol. 46, no. 9, pp. 635-638, 2002.

[13] T. Fang, S. J. Kennedy, L. Quan, and T. J. Hicks, “The structure and paramagnetism of Ni3Nb," Journal of Physics: Condensed Matter, vol. 4, no. 10, article no. 007, pp. 2405-2414, 1992.

[14] A. Boultif and D. Loueer, "Indexing of powder diffraction patterns for low-symmetry lattices by the successive dichotomy method," Journal of Applied Crystallography, vol. 24, no. 6, pp. 987-993, 1991.

[15] J. Rodriguez-Carvajal, M. T. Fernandez-Diaz, and J. L. Martinez, "Neutron diffraction study on structural and magnetic properties of La 2NiO4," Journal of Physics: Condensed Matter, vol. 3, no. 19, article no. 002, pp. 3215-3234, 1991.

[16] H. M. Rietveld, "A profile refinement method for nuclear and magnetic structures," Journal of Applied Crystallography, vol. 2, p. 65, 1969.

[17] P. Nash and A. Nash, "The Nb-Ni (Niobium-Nickel) system," Bulletin of Alloy Phase Diagrams, vol. 7, no. 2, pp. 124-130, 1986.

[18] I. Kirman, "Precipitation in the Fe-Ni-Cr-Nb system," Journal of the Iron and Steel Institute, vol. 12, pp. 1612-1618, 1969.

[19] C. Boudias and D. Monceau, "CaRine Crystallography," (1989-2003), http://pro.wanadoo.fr/carine.crystallography/.

[20] http://imagej.nih.gov/.

[21] J. P. Zhang, H. Q. Ye, K. H. Kuo, and S. Amelinckx, "Highresolution electron microscopy study of the domain structure in Ni//3Nb. II. Orientation and general domains," Physica Status Solidi (A), vol. 93, no. 2, pp. 457-462, 1986.

[22] C. L. Chen, W. Lu, Y. Y. Cui, L. L. He, and H. Q. Ye, "Highresolution image simulation of overlap structures in TiAl alloy," Journal of Alloys and Compounds, vol. 468, no. 1-2, pp. 179-186, 2009. 

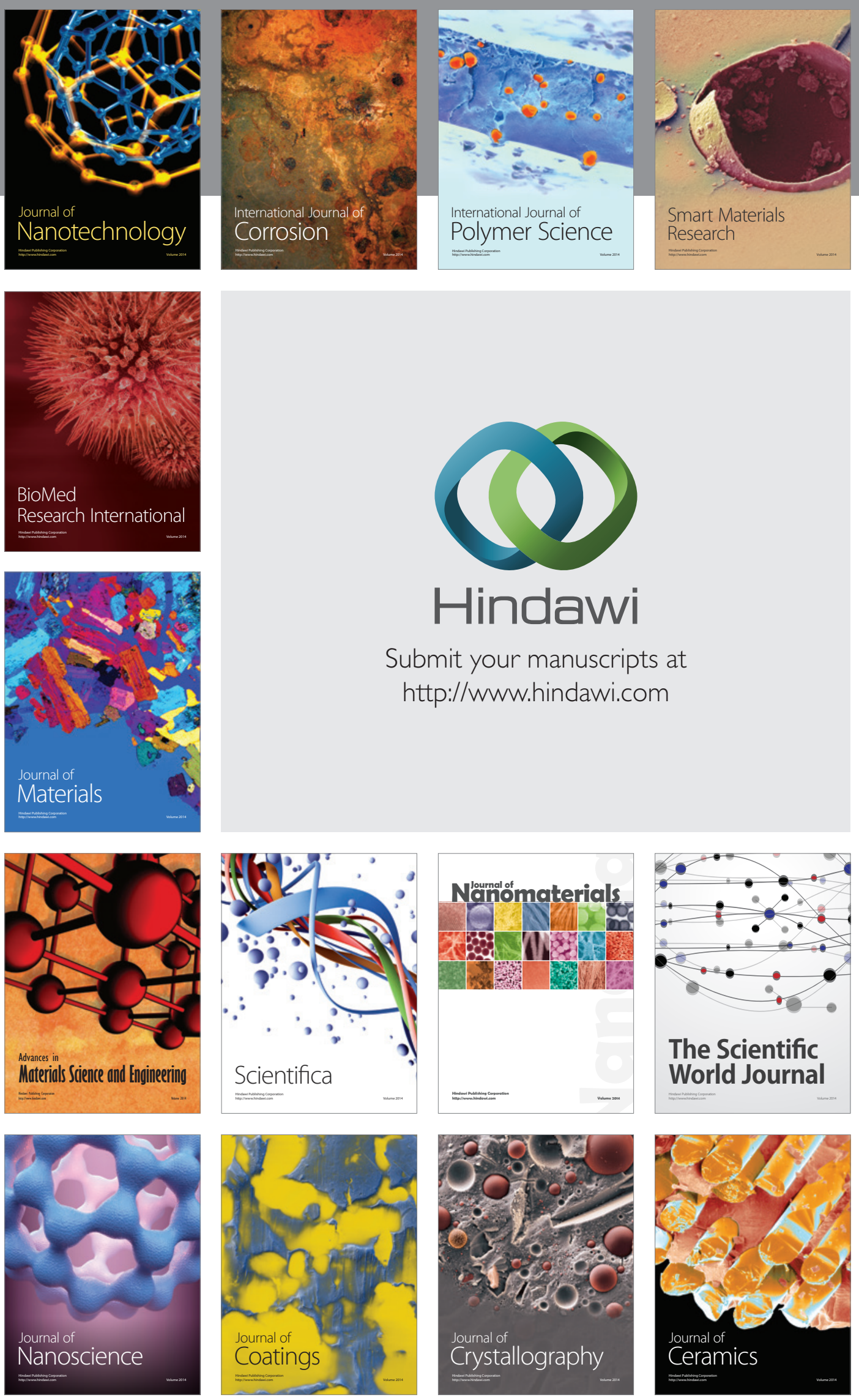

The Scientific World Journal

Submit your manuscripts at

http://www.hindawi.com

\section{World Journal}

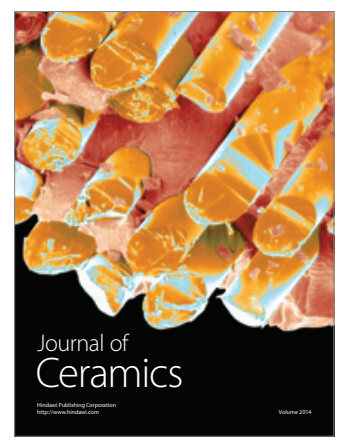

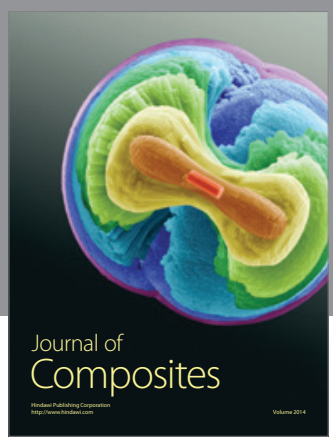
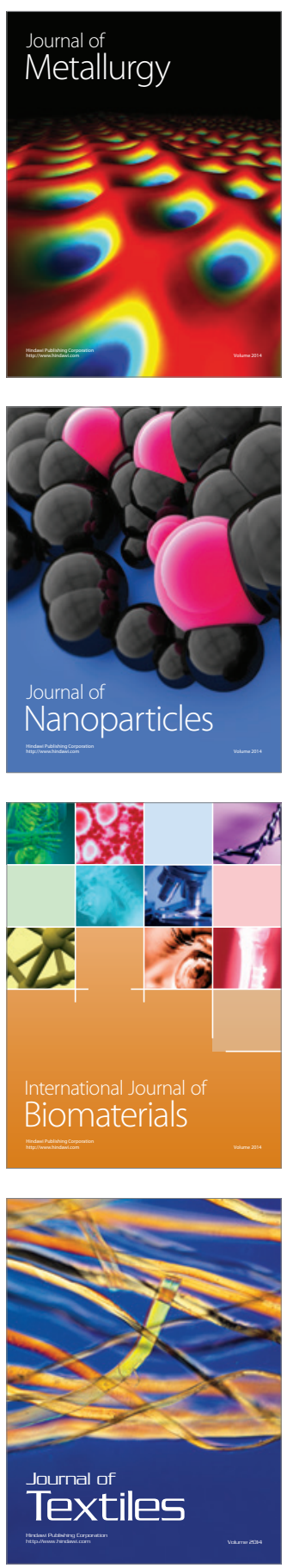